\title{
Young People's Gender and Identity Work in a Swedish Internet Community
}

\author{
Malin Sveningsson Elm \\ Karlstad University, Sweden \\ malin.sveningsson@kau.se
}

\begin{abstract}
One of the most popular Swedish online meeting places is the community portal Lunarstorm, which is visited above all by young people. During the last years, media has described how teenage girls have been contacted at Lunarstorm and lured into sexual activities. This in turn has led to further discussions on the way teenagers present themselves online. The adolescence is a time to explore identity and to find out who one really is. The way to an independent identity goes through experimenting, and it is important to find places where this can be done away from the surveillance of the adult generation. Here, online meeting places may have an important part to fill. This paper is a presentation of a research project (2005-2007) that sets out to study what role Lunarstorm plays in the identity work of young Swedes. It presents the methodological and theoretical points of departure, and summarizes the main findings of the project.
\end{abstract}

\section{Introduction}

One of Sweden's most frequented meeting places is the community portal Lunarstorm ${ }^{1}$. Lunarstorm is especially popular among young people, and it is the web site where young Swedes spend most time - on average 45 minutes a day. Half of the users are under 18 years old, the single largest group found among 15 to 20 year-olds. Within this group, $85 \%$ of all Swedes visit Lunarstorm at least once a week and $29 \%$ every day $^{2}$. In other words, Lunarstorm is a place where young people hang out together and thus a place where much identity work is done.

Young people's use of meeting places online implies that the means for adults, such as parents and teachers, to get insight into and control what young people do may decrease. This, in turn, has often lead to moral panics [1]. Popular culture has often been interpreted as threats towards young people. The reason being that it is often associated with the leisure time of the young or with the borderlands between family, school and work upon which the fosterers have limited possibilities to exercise control [2]. The mass media play an important part in this process, and to a great extent create it by describing the phenomenon in a stereotypical, exaggerated or even erroneous way. During the last years, Swedish media have addressed the issue of youngsters' doings in Lunarstorm. Girls and young women have been reported to be

\footnotetext{
${ }^{1}$ www.lunarstorm.se

${ }^{2}$ Statistics available at: www.lunarworks.se, Nov. 2005.
} 
contacted in Lunarstorm, and persuaded to pose in pornographic pictures, or lured into sexual contacts. These stories have caused discussions on the way young women and teen age girls present themselves in their personal pages in Lunarstorm, where presentations of self are often said to be sexually provocative ${ }^{3}$.

The discourse on young women's presentations of self in Lunarstorm evokes questions on girls' and women's sexuality, which has often been seen as a threat, both to society and to the women themselves [3]. It is often not even acknowledged, but women are rather seen as victims being abused by male predators. Media discourse affects public ideas, and many parents and educators think of internet use as a potential danger to their girls [4]. The question, however, is how true these images are. Of course it does occur that young women are abused and persuaded into doing things they would rather not have wanted to do, but the point is that media coverage is quite one-sided. On the whole, it reproduces the image of women as weak and (sexually) passive and of men as strong and (sexually) active. Furthermore, for those with personal experiences of Internet communication and -communities, the image depicted in media appears quite unfamiliar. In general, online communities are not fora where all inhibitions are dropped and users engage in wild orgies of pornographic exposures of self (unless the forum is explicitly focused on pornography and sexual activities of course).

However, I had no previous experience of the specific web community Lunarstorm, and decided to see what things really looked like there. Other questions I had in the start of this project were how young women's attitudes towards sexuality really look today, and what part meeting places on the Internet, such as Lunarstorm, play in these attitudes, as well as in the social practices of young women. Could the Internet be seen as a space where they can, in a relatively safe way, experiment with sexuality and gender identity, and where an exposure of the body can be done in another way, perhaps with a different meaning, than in offline environments? Another side of the problem is that media stories were all about young women, while young men's presentations of self were not discussed at all. However, meeting places like Lunarstorm imply new means for young men too to develop identity, experiment with sexuality and try out new, alternative gender identities - identities that they might not otherwise have been able to explore, due to constraints and expectations put on them from society [cf. 5 , in her study on bisexual young men living in a small town].

This project takes as point of departure the assumption that meeting places on the Internet may play an important part in both men's and women's gender- and identity work. The aim of the project was to look at the function Lunarstorm fills in young Swedes' gender- and identity work.

\footnotetext{
${ }^{3}$ Paradoxically enough, Lunarstorm is known to be a relatively secure web community, with much social control and regulated behavior among its users. The owners of Lunarstorm also cooperate with the Swedish police, in order to prevent crimes such as for example prostitution and child pornography.
} 


\section{Identity and identity work}

In society today, the individual has increasingly come to be seen as creating $\mathrm{him} /$ herself [6]. This view of identity as "doable" is one of the premises of this analysis, which is also revealed by my choice of the phrasings "identity work" and "identity construction". I here side with the view of identity not as a stable and static entity, but rather as a dynamic and changeable property, which, in its making, needs to be performed in front of others, and is elaborated in dialogue with others. I.e., individuals construct their identities in the interaction with other human beings [cf. 7 , 8].

As Giddens [9] says, modernity confronts individuals with a complex abundance of choices, but at the same time, it offers little guidance as to what they should choose. This dilemma is perhaps especially difficult for young people. The adolescence is a period of exploring identities, where the eternal question seems to be "Who am I?" Young people of today are not bound by the constraints of rules and norms of old patterns of life, which implies a freedom to find their own way of life [10]. However, it also implies that they stand without the support that traditions used to be for the individual's choices of life. They are expected to make decisions and form identities on their own, in a world where the power of authorities have diminished, and where, at the same time, there is an abundance of different roles and ideals to choose between. This may be especially difficult for young women, who have to deal with many conflicting ideas of what femininity is, and what it means to be a woman [11], but neither for young men is it an easy task to relate to the often contradictory ideals of masculinity [cf. 12, 13].

The way to independence goes through experiments. Therefore, says Ganetz [10], one of the distinctive marks of youth culture is the seeking for places where one can decide for oneself, and be on one's own with peers, without the interventions from either parents or grown up representatives of authorities. These places, says Ganetz, are absolutely necessary for the individual to seek, experiment with and create an own identity. The free spaces of boys have traditionally been territories set up in public places. For girls and women, on the other hand, streets and other public spaces have often been experienced as dangerous places to be in, and visibility in public has therefore often been the privilege of boys and men [14]. Girls have instead mainly sought their free spaces in the home, at shopping malls, or other places that offer some security, but which on the other hand also are supervised in one way or another. The Internet could here have an important part to play, being a public, unsupervised arena, although visited from secure places like the home, school or library. Even though researchers and media alike have pointed at harassment and inequalities online [1517], the internet has also frequently been called a "safe haven" for women, and for girls engaging in identity work [4, 18-20]. Here, they can try out various roles and identities, in safety at home, while at the same time the medium provides them with an audience in which to mirror themselves in their identity work. However, the aspect of security is important not only for women - men who display alternative gender identities may also profit from the absence of physical reprisals as a consequence of their performances. 


\section{Gender as created and performed}

This project has a constructivist perspective, which holds that gender properties are not inherently written into individuals' minds. A male body is not necessarily followed by a male gender. Rather, gender is created, or "done". Gender is created by being performed: it is not a cause of, but rather an effect of different sorts of actions [21] Enacting and displaying certain properties that are generally associated with one specific gender thus becomes the means through which gender is created. People constantly "do" gender, i.e., they make performances that display characteristics that are thought of as masculine or feminine, and in doing so; they construct themselves to fit into one of the categories men or women. As Goffman [22: 7] puts it:

"What the human natures of males and females really consists of, then, is a capacity to learn to provide and to read depictions of masculinity and femininity and a willingness to adhere to a schedule for presenting these pictures, and this capacity they have by virtue of being persons, not females or males. One might just as well say there is no gender identity".

Individuals always play different roles in different contexts [8]. When an activity takes place in the presence of other people, the actor performs so as to accentuate some aspects of self, while suppressing others. The aspects of self that are accentuated typically correspond to norms, conventions and ideals that are embraced in the group that the actor belongs to, or wishes to belong to. In all groups, some norms have higher status than others, implying that some behavior gives more "rewards" than others, typically in the form of positive (or lack of negative) responses from the audience. This means that characteristics that are highly valued within the group are likely to be displayed more frequently than characteristics with lower value.

This is also applicable to gender performances, as some kinds of masculinities and femininities get more rewards than others. There are many co-existing kinds of masculinity that relate to each other [23]. The concept hegemonic masculinity is defined as "the configuration of gender practice which embodies the currently accepted answer to the problem of the legitimacy of patriarchy, which guarantees (or is taken to guarantee) the dominant position of men and the subordination of women" [23: 77]. Hegemonic masculinity is the form of masculinity that is the most valued in a certain society at a given time. What is valued depends on the societal context, and what is hegemonic is therefore changeable in time and space. However, it is important to note that far from all men fit into the ideals of hegemonic masculinity, which should be seen more as an ideal to relate to. As Connell [23: 78] says, "hegemony relates to cultural dominance in the society as a whole. Within that overall framework there are specific gender relations of dominance and subordination between groups of men". Some masculinities are for example seen as complicit, i.e., consisting of men who take advantage of men's privileged position without themselves living up to the ideals of hegemonic masculinity. Other masculinities are seen as subordinated, i.e., those that are associated with femininity, among which homosexual men are the most obvious [23].

There is no equivalent - no hegemonic femininity - that can be directly applied to women. Because hegemonic masculinity implies men's superior position relative to 
women, the notion of hegemony is difficult to translate to processes and power relations between women [24]. Inspired by Beverley Skeggs, Fanny Ambjörnsson states that there still exist different kinds of femininity, which are valued differently and which hold different positions relative to each other. Ambjörnsson calls the most highly valued femininity "normative femininity" [24: 29].

\section{Presentation of self}

Besides theories on gender and identity I have also been using theories on the presentation of self, most notably Goffman's concepts of back stage and front stage, and audience segregation [8]. The concept 'front stage' refers to when the actor is involved in doing a performance. The concept can be divided into two aspects: the 'setting', which is the place where the performance takes place, and the 'personal front', which can refer either to the equipment or items needed to perform, or to the personal characteristics of the actor. 'Back stage', on the other hand, is when the performing person, the actor, is present but the audience is not. The actor is either alone, or in a group in which the members cooperate around the performance - a team. Back stage is a place or a situation, in which the actor can relax and step out of character, and it can be used for preparing and rehearsing the role until it is time to step out before the audience again ${ }^{4}$.

The sections above have hinted at how norms and ideals may differ between various settings. This is something that the socially skilled individual always has to deal with when performing in front of others, because the different roles played by the same individual in different contexts may, most probably, sometimes be inconsistent. Actors therefore try to keep contexts and audiences apart, in order to be spared from embarrassment resulting from conflicting roles. This process is called 'audience segregation' by Goffman.

\section{Method}

In Lunarstorm, users create "krypin" (or "dens", in English), which are their own personal sites on Lunarstorm, where they present themselves. Here, I looked at how young men and women represent themselves. How is femininity and masculinity performed? Are gender identities expressed in a stereotypical way or does the medium encourage users to express new, alternative forms? And if so, what do they look like?

Lunarstorm has a friend finder facility where users can specify the characteristics of other users they wish to find. To get a sample of users, I used this friend finder facility, specifying age and gender, while letting city of residence vary with users.

${ }^{4}$ It should be noted that 'back stage' is a relative term and exists only in relation to a specific audience. Whenever performers are not alone, they are in a performance. In the back region, another performance may be given before the other team members, although typically, the roles that the actor performs before different audiences will be different. 
This was done in turn for female users 15,16, 17, 18 and 19 years old, and for male users of the same age groups. This resulted in a sample of 50 users from each age and gender group, i.e., 500 in total ${ }^{5}$. At the time I collected my data (2004-2005), nests could have 13 sub-pages: pres, guest book, diary, friends, clubs, roots, hot, quiz, lists, collage, stuff, party and status. In this study, I chose to delimit the scope of study to three sub-pages: pres, stuff and collage pages ${ }^{6}$.

A quantitative content analysis was made of the "pres", "stuff" and "collage" pages of all 500 nests. Quantitative content analysis has been described as the objective, systematic and quantitative presentation of the manifest content of a message [25]. As other quantitative methods, it is supposed to be independent of who is doing the analysis, and so the units of analysis (i.e., what parts of the content are to be counted) are usually decided and fixed before the analysis takes its start. In other words, content analyses are usually deductive. However, in this study, the approach was inductive. In the analysis, I looked for what aspects of self the young people expressed in their nests, but I did not know beforehand which aspects these would turn out to be. I therefore let the data gradually give rise to the categories for analysis. The method used could thus be described as a hybrid - quantitative content analysis with streaks of thematic analysis or grounded theory [26], or the other way around: a thematic analysis where the resulting categories became subject to a statistical analysis.

The analysis started with the pres page of each nest. There, all components such as texts, links, pictures and other graphical elements, as well as the graphic design were described. Similar inventories were made for the stuff and collage folders. I wrote brief descriptions of 50-250 words of each nest, and classified them according to what aspects of self each user emphasized. These aspects of self will in the following text be referred to as "themes". I chose not to limit myself to a certain number of themes, but all themes that were expressed were included. The number of themes per nest therefore ranges from 0 to 23 , with a mean of 4.28 and a median of 4 . When classifying the themes, no consideration was taken into how large extent a certain theme was stressed, but data were treated on a nominal scale where all cases of occurrence were given the value one and the rest of the cases the value zero.

${ }^{5}$ Information about age and gender is acquired automatically by Lunarstorm's software in the registration process, i.e. when the users provide their personal number. Even if this decreases the risk of gender crossing, it is of course still possible that some of the users have provided fake numbers to appear to be of another gender or age than is actually the case.

${ }^{6}$ The pres is where visitors arrive when clicking other users' name links. Here, first impressions are created, and visitors decide whether to proceed to look at the other subpages, sign the guest book or take other initiatives to contact. Pres pages vary greatly in how much information users provide. Some do not give any information at all, besides the user name. Others write detailed descriptions about themselves, their background, interests and relationships to other people. On "stuff" pages, users publish material such as photos, texts, drawings, sound files, video clips, links to web sites and other material. "Collage" pages work like photo albums. The main difference from the stuff page is that the material is more clearly organized and that users have more disk space at their disposal and can thus publish more material. 
Analyses have been made on the whole as well as on parts of this material, where I used the large study as a point of departure and entered more deeply into aspects that I saw as specifically interesting. I have here used different types of sample procedures and analysis methods. Quantitative analyses (frequencies and crosstabs) were made with SPSS. Qualitative analyses included thematic analyses, case studies, and analyses of pictures, done on material strategically chosen with respect to its content.

\section{Results}

A survey of the material resulted in 94 different themes that were grouped into 20 categories. The categories with least number of occurrences (i.e. those stressed by less than $2 \%$ of both men and women ${ }^{7}$ ) were sorted out, leaving us with 16 categories as shown in table 1 .

Table 1. Categories of orientations

\begin{tabular}{|l|c|c|c|c|c|c|}
\hline & $\begin{array}{c}\text { Men } \\
\%\end{array}$ & $\begin{array}{c}\text { Women } \\
\%\end{array}$ & $\begin{array}{c}\text { Men } \\
\text { Sum }\end{array}$ & $\begin{array}{c}\text { Women } \\
\text { Sum }\end{array}$ & Significance $^{8}$ & N \\
\hline Relationships & 58,4 & 79,2 & 146 & 198 & $* * *$ & 344 \\
\hline Culture & 47,2 & 47,2 & 118 & 118 & - & 236 \\
\hline Feelings & 18,4 & 30,4 & 37 & 76 & $* * *$ & 113 \\
\hline Sport & 25,2 & 18 & 63 & 45 & - & 108 \\
\hline Animals & 7,6 & 29,2 & 19 & 73 & $* * *$ & 92 \\
\hline Humor & 21,6 & 14,4 & 54 & 36 & $*$ & 90 \\
\hline Exposure of Body & 14,4 & 20,8 & 36 & 52 & - & 88 \\
\hline Party & 12,8 & 20,8 & 32 & 52 & $*$ & 84 \\
\hline Motorvehicles & 23,6 & 7,6 & 59 & 19 & $* * *$ & 78 \\
\hline Work \& Education & 11,2 & 18,4 & 28 & 46 & $*$ & 74 \\
\hline Exposure of Status & 14 & 5,2 & 35 & 13 & $* * *$ & 48 \\
\hline Technology & 14,4 & 6 & 36 & 15 & $* *$ & 51 \\
\hline Politics & 6,8 & 6,4 & 17 & 16 & - & 33 \\
\hline Heterosexuality & 8,4 & 2,8 & 21 & 7 & $* *$ & 28 \\
\hline Ethnic origin & 3,6 & 3,6 & 9 & 9 & - & 18 \\
\hline Cooking & 1,2 & 5,2 & 3 & 13 & $*$ & 16 \\
\hline
\end{tabular}

Juxtaposing the presentations of young men and women, we see that the young men are in the majority in the categories humor, motor vehicles, exposure of status, technology, and heterosexuality. The young women, on the other hand, are in the majority in relationships, feelings, animals, party, work and education, and cooking. Hence, even though differences were not significant for the categories culture, sport,

${ }^{7}$ Those were nature, hunting and fishing, religion and gambling.

${ }^{8}$ The asterisks * mean that the difference is significant. ${ }^{*} \mathrm{p}<0.05{ }^{* *} \mathrm{p}<0.01 \quad{ }^{* * *} \mathrm{p}<0.001$ 
politics and exposure of physical body, in the rest of the categories we see that the expressed interests follow a strongly gender stereotypical pattern as described by authors such as Connell [23], Davies [27], Frosh et al, [28], Skeggs [3], Svahn [29] and Walkerdine [30].

Practising and displaying one's interests can be seen as one type of gender work [cf. 6], and of doing gender. Frosh et al (2002), for example, saw that for young men in Britain, it was important to display and stress an interest in football in order to be seen as properly masculine. The young men who did not have this interest (or pretended to have it) often ran into problems with their peers, being considered feminine (and thereby put under suspicion to be homosexual and as such seen as nonmen, or at least subordinated (Connell, 1995)). This strong polarization was not found in my data, at least not in relation to sport, which is quite evenly distributed among men and women. In general other aspects seem to be seen as more gender specific than sport. ${ }^{9}$ The categories that host the biggest gender differences are motor vehicles $(76 / 24)$, heterosexuality (75/25), exposure of status $(73 / 27)$, technology $(70 / 30)$, feelings (33/67), animals (21/79), and cooking (19/81). It is thus likely that these aspects are seen as more important to stress in order to appear as 'proper' young men respectively women. On the other hand, however, the number of users who do stress aspects belonging to these categories is in many cases not very large, so it does not seem to be compulsory in the way the interest in football seemed to be in Frosh et al.'s study (2002). One could perhaps turn it the other way around and say that in the Lunarstorm material, users rather tend to not display interests that are associated with the other gender, since this could put their gender identities into question.

\section{Analyses on parts of the material}

Within the project, analyses have also been done on parts of the material. In Young men's gender- and identity work in a Swedish Web community[31], the sample consisted of 250 male users, and was a quantitative overview of what aspects of self was presented and displayed. The gender representations of the boys were found to be quite stereotypical, as defined by authors such as [23, 24, 28, 29, 32], and represented in the users' spheres of interest and personal characteristics displayed. However, exceptions were found in the young men's' strong focus on social relationships and romantic feelings Similar tendencies were found in statistics on offline conditions [33], implying that it may be a question of changing masculinities rather than the

${ }^{9}$ It should, however, be noted that sport was one category, and not divided into several subcategories according to different branches of sport. It is likely that there are some differences here, whereas more young women would be more attracted to sports like aerobics, gymnastics and horseback riding, and more men to sports such as football and ice hockey. Even if this was not analyzed, there were a good deal of young women who displayed a strong interest in football and ice hockey, both as practisers and as fans. However, no young men displayed an interest in aerobics and gymnastics, and extremely few in horseback riding. 
medium making a difference, although the medium and the specific community may further encourage these changes.

The study Young people's presentations of relationships in a Swedish Internet community[34], dealt with the users' presentations of relationships. Here, the sample was one whole category, or more exactly the dens of the 339 users who had addressed relationships. The aim was to look closer at how, and by whom various types of relationships were addressed. In many respects, the presentations of relationships follow a gender stereotypical pattern, and this goes for all types of relationships included in the material: friendships, family relationships and romantic relationships. More women than men emphasize relationships, and they also express stronger feelings about them. However, one exception was found in the way romantic relationships were addressed, where both men and women expressed strong feelings towards their relationships and partners. All of the addressed romantic relationships were heterosexual, and in the whole sample, only one user explicitly claimed to be other than straight. This was somewhat surprising - it does not reflect the fact that a certain percentage of the population is bi- or homosexual. Some of this can probably be explained by the users being too young to have tried out and felt their way vis à vis their sexual orientation, or if they have, not be willing to come out with it. But the most important explanation probably lies in norms and ideals of what is accepted, what implies status and what is seen as stigmatizing within the community. Heterosexual relationships are generally seen as desirable, while non-heterosexual desires, activities and identities are generally seen as stigmatizing, especially for boys (Frosh et al., 2002; Connell, 1995).

In the study Doing and undoing gender in a Swedish Internet community [35], I took a closer look at how stereotypes may be transgressed. I here used a strategic sample, and made a thematic analysis of 2 cases, corresponding to users who deviated from the pattern and transgressed gender stereotypes. The analyses illustrate how complex young people's presentations of self may be, where various characteristics, interests and orientations intertwine, carrying with them different, sometimes contradictory and conflicting images of masculinity and femininity that have to be balanced against each other. It was, for example, found that even though the users on a conscious level try to break free from constraining stereotypes, it seems as they still at least partly end up in traditional patterns of gender, where some structures seem to be more difficult to get rid of than others. There seems to be some fundamental and tenacious structures that largely remain unchanged and which express themselves in what individuals communicate about themselves without thinking about it (c.f. Goffman's [8] concepts expression given and expression given off ${ }^{10}$ )

The study Young people's exposure of bodies in a Swedish Internet community[36, 37] aimed at looking at young men's and women's presentations of

10 "Expression given" involves verbal symbols or their substitutes, which are used deliberately to convey the information attached to these symbols. "Expression given off", on the other hand, consists of a wide range of actions that others can treat as symptomatic of the actor, where the purpose is other than conveying information. It can for example consist of tone of voice, body language, facial expressions, blushes, etc, and it often provides a great deal of information about the actor that $\mathrm{s} / \mathrm{he}$ never intended to convey. 
self, focusing specifically on how and by whom bodies were displayed. The sample consisted of a whole category, exposure of physical body, or more exactly, the 941 photographs of the 88 users included in the category, which depicted the users alone. The method was mainly quantitative. Results showed differences in what parts of their bodies the young men and women show: women tend to focus on faces, while the men on torsos. Results also contradicted the image depicted by media, as very few photos could be described as provocative. An explanation is here offered by the specific internet community's lack of anonymity and lack of means of audience segregation, meaning that the interaction is steered by the same mechanisms and social pressure as in offline environments, and that the users must balance their presentations of self so as to fit several possible audiences at the same time.

In Exploring and negotiating femininity: Young women's production of style in a Swedish internet community[38], the aim was to look at how teenage girls use their production of style in their identity work in their dens. Here, a strategic sample was employed, using the dens of 11 girls, who, in comparison with the majority of the 500 users of the first sample seemed to experiment much with looks and styles online, i.e., these girls had published a large number of photos of themselves, where they wore different outfits and accessories, and showing many different postures and facial expressions. Results showed how girls can explore and experiment with different sides of femininity, but also how they may balance between undesired extremes. In this way, the girls' room online may serve as a tool for identity construction.

In Taking the girls' room online: Similarities and differences between traditional girls room and computer-mediated ones[39], I compare the traditional girls' room offline with girls' dens at Lunarstorm. Despite many similarities as concerns what activities are performed, the differences in terms of publicity and privacy makes it impossible to talk about the den as an equivalent to the traditional girls' room. Or, in Goffman's terminology [8], the traditional girls' room can be seen as a back stage region while the computer mediated girls room, with all its potential spectators, is more properly described as front stage.

\section{Conclusions}

The findings have contradicted some commonly held assumptions: Lunarstorm, being an online arena, would offer opportunities for more experimenting and exploration with gender identity and sexuality than offline environments; users would feel freer to abandon traditional gender stereotypes and more likely to expose alternative gender identities and sexualities, a plentitude of exposures of bodies, perhaps being done in different conditions than in offline settings. None of this turned out to be true. Instead, the youngsters' presentations of self turned out to follow quite stereotypical patterns both in terms of gender and of sexuality. However, the gender representations showed some interesting exceptions and contradictions, especially in the young men's strong focus on relationships, especially romantic ones. There are also exceptions that consist of single users' more or less conscious attempts at transgressing norms and stereotypes. But the analyses also show that presentations of self are complex, with 
different markers of masculinity and femininity co-existing in each presentation of self, sometimes conflicting with and contradicting each other. Often users end up in stereotypical ideals anyway, even though they may try to avoid it. However, one interesting discovery was that the dens are used in a way that is much reminiscent of how traditional girls' rooms are used, where girls, alone or more often together with friends, work out and experiment with style and appearance, and thereby explore their relation to femininity. The dens can thus be an important part in their elaboration and acquiring of a female gender identity.

As for the issue of sexuality, it can be argued that the absence of references to queer identities is not surprising, considering the fact that there are other online communities that specifically address such target groups. However, considering the fact that 85 per cent of all Swedish youngsters in the chosen age group are members of Lunarstorm, it is likely that at least some of them have other sexual orientations than heterosexual, and the sample of 500 Lunarstorm users should thus include at least a few such individuals. The point here is not to find out exactly how many these may be. Rather, it is to point to the lack of references to other romantic relationships, practices and desires than heterosexual as a sign of the heteronormative character of Lunarstorm, where the absence of such references clearly shows that queer, or nonheterosexual, identities are not highly valued within the community.

As for the ways bodies are presented, contrary to the image being shown by popular media, the analyses show that very few of the photos that the youngsters display classify as sexually provocative.

There are several explanations to these results. The fact that Lunarstorm follows such a gender stereotypical and heteronormative pattern and that users appear so sexually moderate may have at least three explanations. First, we have the culture of a specific Internet community. The managers of Lunarstorm have taken measures to make it a safe and friendly place - they cooperate with the Swedish police and organizations that aim at protecting children, to prevent prostitution and pornography, but also other harassment. The culture of the overarching community can be described as mainstream and decent.

The second explanation lies in the lack of anonymity and the connections between users' online and offline identities. Even if being a large community, members mostly use Lunarstorm to hang out with friends and interact with people they already know from their local offline environments [40, 41], meaning that despite its size, Lunarstorm is clearly locally anchored. Due to the connections between on- and offline identities (i.e., that users mainly interact with people from their offline lives), everything that users do at Lunarstorm will cause repercussions in their daily life offline, in school for instance.

A third explanation can be found in Lunarstorm's attraction of a large and wide audience. Previous research has pointed at the difficulties that users of online arenas may experience in their presentations of self, due to the variety and heterogeneity of their audiences [see, for example, $42,43,44]$. In many online arenas, such as publicly accessible personal web sites or blogs, the heterogeneity of the audiences comes with the open interface. As for other arenas, which require registered membership, as boyd and Heer note, users may not have foreseen the dramatic growth of these arenas into 
unexpected audiences. This is clearly the case for Lunarstorm users too, only that they are fully aware of the possibility of getting their presentations read by unintended audiences. The users show a clear awareness of that audience segregation is not possible. Since users know it is impossible to keep audiences apart in this specific forum, they tend to form their presentations of self so as to fit into several different contexts at the same time. It would likely take quite some competency for the young people to, in their minds, position themselves in various situations, contexts and groups, and designing a presentation of self that manages to fit into all of them, while at the same time not transgressing the norms and standards of conduct of any of them. Not only do the young men and women have to balance between undesired polarities of gender ideals, but they also have to foresee situations where people from their different spheres of life may come and watch their presentations. As Lunarstorm is so widespread among youngsters, parents and teachers, for example, often register as members to be able to see what their children are doing during their leisure time ${ }^{11}$.

Bearing this in mind, the absence of alternative gender identities, sexualities and provocative material is perhaps not surprising after all - this kind of material is probably rather found in arenas that are more anonymous and that allow more of audience segregation, i.e., which are not so openly available. It would be interesting to do a comparison with such communities, because it is probably in such arenas that more progressive presentations of self can be found, both in terms of gender and of sexuality. There are however methodological issues for such studies: the researcher has to get access to the secluded places and must be able to conduct the research without violating people's right to privacy. But that's another question.

\section{References}

1. S. Cohen, Folk devils and moral panics: the creation of the mods and rockers, MacGibbon \& Kee, 1972.

2. U. Boëthius, "Ungdomar, medier och moraliska paniker," Ungdomar i skilda sfärer5, J. Fornäs, et al., eds., Bruno Östlings förlag Symposion, 1993, pp. 257-284.

3. B. Skeggs, Att bli respektabel, Daidalos, 1997.

4. S.M. Thiel, "IM me," Girl wide web. Girls, the Internet, and the negotiating of identity, S. R. Mazzarella, ed., Peter Lang, 2005, pp. 179-202.

5. H. Bertilsdotter, "Att fetischera det "normala". Bisexualitet utifrån några unga mäns berättelser," Sexualitetens omvandlingar. Politisk lesbiskhet, unga kristna och machokulturer, T. P. Johansson \& Lalander, ed., Daidalos, 2003, pp. 239-270.

6. K. Drotner, At skabe sig - selv. Ungdom, aestetik, paedagogik, Gyldendal, 1991/1996.

7. G.H. Mead, Mind, Self, and Society, University of Chicago Press, 1934.

8. E. Goffman, The Presentation of Self in Everyday Life, Penguin books, 1959/1990.

9. A. Giddens, Modernity and self-identity. Self and society in the late modern age, Polity Press, 1991.

${ }^{11}$ Boyd \& Heer [43] noted similar issues in another online social forum, but boyd and Heer's concern was how users had not foreseen that their employers would enter into the same community and thus get access to information and in-jokes that were shared between them and their friends. 
10. H. Ganetz, "Butiken, hemmet och kvinnligheten som maskerad. Drivplatser och platser för kvinnligt skapande," Unga stilar och uttrycksformer, J. Fornäs, et al., eds., Bruno Östlings förlag Symposion, 1992, pp. 203-240.

11. A. Göthlund, Bilder av tonårsflickor. Om estetik och identitetsarbete, Linköping studies in Art and Science, 1997.

12. J. Andréasson, "Brudar, bärs och bögar - maskulinitet och sexualitet i en enkönad miljö," Sexualitetens omvandlingar. Politisk lesbiskhet, unga kristna och machokulturer, T. Johansson and P. Lalander, eds., Daidalos, 2003, pp. 25-46.

13. N. Hammarén, "Horor, players och de Andra. Killar och sexualitet i det nya Sverige," Sexualitetens omvandlingar. Politisk lesbiskhet, unga kristna och machokulturer, T. Johansson and P. Lalander, eds., Daidalos, 2003, pp. 95-124.

14. L.A. Lewis, "Being Discovered: The Emergence of Female Address on MTV," Sound and Vision: The Music Video Reader, L. Grossberg, et al., eds., Routledge, 1993, pp. 129-152.

15. L. Cherny and E. Reba Weise, eds., Wired women : gender and new realities in cyberspace, Seal Press, 1996.

16. S. Herring, "Gender and democracy in computer-mediated communication," Electronic Journal of Communication, vol. 3, no. 2, 1993.

17. S. Herring, "Gender Differences in Computer-Mediated Communication: Bringing Familiar Baggage to the New Frontier," Proc. American Library Association annual convention, June 27, 1994.

18. S.R. Stern, "Adolescent girls' expression on web home pages. Spirited, sombre and selfconscious sites.," Convergence, vol. 5, no. 4, 1999, pp. 22-41.

19. S.R. Stern, "Expressions of identity online: prominent features and gender differences in adolescents' world wide home pages," Journal of Broadcasting \& Electronic Media, vol. 48, no. 2, 2004, pp. 218-243.

20. A.D. Grisso and D. Weiss, "What are gURLs talking about? Adolescent girls' construction of sexual identity on gURL.com.," Girl Wide Web. Girls, the Internet, and the Negotiation of Identity, S. R. Mazzarella, ed., Peter Lang, 2005, pp. 31--50.

21. J. Butler, Gender Trouble. Feminism and the subversion of identity, Routledge, 1990.

22. E. Goffman, Gender Advertisements, Macmillan, 1976.

23. R.W. Connell, Masculinites, University of California Press, 1995.

24. F. Ambjörnsson, I en klass för sig. Genus och sexualitet bland gymnasietjejer, Ordfront, 2004.

25. H. Østbye, et al., Metodbok för medievetenskap, Liber, 2003.

26. A. Strauss and J. Corbin, Basics of Qualitative Research. Grounded Theory Procedures and Techniques, SAGE, 1990.

27. B. Davies, Hur pojkar och flickor gör kön, Liber, 2003.

28. S. Frosh, et al., Young masculinities, Palgrave, 2002.

29. M. Svahn, Den liderliga kvinnan och den omanlige mannen. Skällsord, stereotyper och könskonstruktioner, Carlsson, 1999.

30. V. Walkerdine, School Girl Fictions, Verso, 1990.

31. M. Sveningsson Elm, "Young men's gender- and identity work in a Swedish Web community," AoIR Internet Annual Volume 4, M. Consalvo and C. Haythornthwaite, eds., Peter Lang, 2006.

32. M. Bäckman, Kön och känsla. Samlevnadsundervisning och ungdomars tankar om sexualitet, Makadam, 2003.

33. SCB, Undersökningarna av levnadsförhållanden., 2003.

34. M. Sveningsson Elm, "Young people's presentations of relationships in a Swedish Internet community,” YOUNG, vol. 15, no. 2, 2007. 
35. M. Sveningsson Elm, "Doing and undoing gender in a Swedish Internet community," Cyberfeminism in Northern lights. Gender and digital media in a Nordic context, M. Sveningsson Elm and J. Sundén, eds., Cambridge Scholars Publishing, 2007.

36. M. Sveningsson Elm, Young people's exposure of bodies in a Swedish Internet community, submitted.

37. M. Sveningsson Elm, “Att visa sin kropp på Nätet. Om ungdomars självpresentationer på Lunarstorm.," LOCUS, no. 1, 2006.

38. M. Sveningsson Elm, "Exploring and negotiating femininity: Young women's production of style in a Swedish internet community.," Book Exploring and negotiating femininity: Young women's production of style in a Swedish internet community., Series Exploring and negotiating femininity: Young women's production of style in a Swedish internet community., ed., Editor ed.^eds., 2007, pp.

39. M. Sveningsson Elm, "Taking the girls' room online: Similarities and differences between traditional girls room and computer-mediated ones," Proc. INTER: A European Cultural Studies Conference in Sweden, ACSIS, 2007.

40. E. Dunkels, "Nätkulturer - vad gör barn och unga på Internet?," Tidskrift för lärarutbildning och forskning, no. 1-2, 2005, pp. 41-49.

41. A. Enochsson, "Ett annat sätt att umgås: yngre tonåringar i virtuella gemenskaper," Tidskrift för lärarutbildning och forskning, no. 1-2, 2005, pp. 81-99.

42. D. Boyd, "Sexing the Internet: Reflections on the role of identification in online communities," Proc. Sexualities, Medias, Technologies, 2001.

43. D. Sevick Bortree, "Presentation of self on the web: an ethnographic study of teenage girls' weblogs," Education, Communication \& Information, vol. 5, no. 1, 2005, pp. 25-39.

44. D. Boyd and J. Heer, "Profiles as conversation: Networked identity performance on Friendster," Proc. Hawai'i International Conference on System Sciences (HICSS-39), Persistent Conversation Track., IEEE Computer Society, 2006. 